\title{
EXPLORING THE MENTAL HEALTH EXPERIENCES OF FIRST GENERATION AFGHAN, POST-SECONDARY STUDENTS IN TORONTO CANADA
}

\author{
By
}

Nargis (Naro) Hussaini, BSW, Ryerson University, 2015

\author{
An MRP \\ presented to Ryerson University \\ in partial fulfillment of the \\ requirements for the degree of \\ Master's of Social Work \\ in the Program of \\ Social Work
}

Toronto, Ontario, Canada, 2017

(C) Naro Hussaini 2017 


\section{AUTHOR'S DECLARATION FOR ELECTRONIC SUBMISSION OF A MRP}

I hereby declare that I am the sole author of this MRP. This is a true copy of the MRP, including any required final revisions.

I authorize Ryerson University to lend this MRP to other institutions or individuals for the purpose of scholarly research

I further authorize Ryerson University to reproduce this MRP by photocopying or by other means, in total or in part, at the request of other institutions or individuals for the purpose of scholarly research.

I understand that my MRP may be made electronically available to the public. 


\begin{abstract}
Exploring The Mental Health Experiences Of First Generation Afghan, Post-Secondary Students In Toronto Canada

Master of Social Work, 2017

Naro Hussaini

Program of Social Work, Ryerson University
\end{abstract}

To explore the mental health experiences of first generation Afghan, post-secondary students in Toronto Canada, qualitative interviews were conducted with three postsecondary Afghan Students from Ryerson University, York University and University of Toronto. This study highlights systemic oppression and institutional barriers that young Afghan adults face as students in post-secondary institutions and the mental health implications faced as a result of on-going prejudice and discrimination. The findings present a compelling case for rethinking the practices and policies that educational institutions have "normalized", using a critical and intersectional analysis in reformulating these practices and policies. The study also highlights the importance of providing a voice to students in planning services and spaces that encourage a sense of belonging and support possibilities for success. 


\section{ACKNOWLEDGEMENTS}

In the loving memory of my mother, without your consistent love and advocacy, this would not have been possible.

I would like to thank my family and friend for their support and encouragement throughout this project. I would also like to thank my participants for giving me the honour to listen and present their stories. Last

but most importantly, I would like to acknowledge Dr. Poole for her consistent direct and indirect teachings of the intersectionalities of Madness; the continuous knowledge sharing and support of my supervisor Dr. G Pon, and the constructive feedback from my second reader Dr. Silver. 


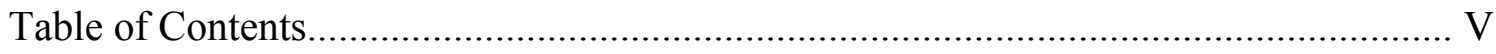

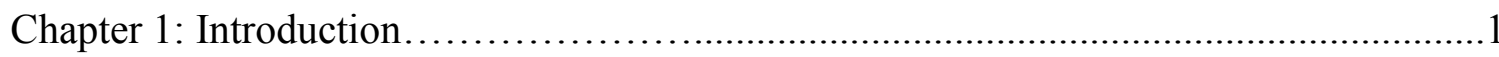

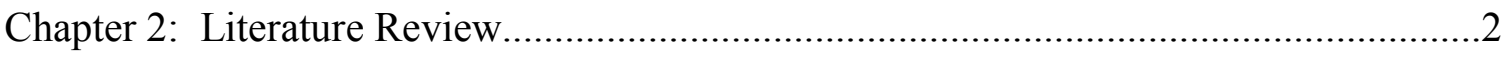

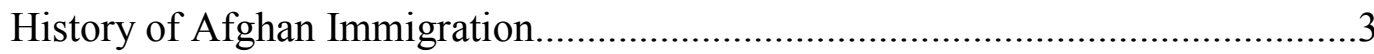

Prejudice and Discrimination............................................................................

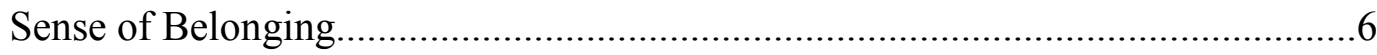

Mental Health of the Immigrant Population...........................................................

Highlights and Limitations...................................................................................13

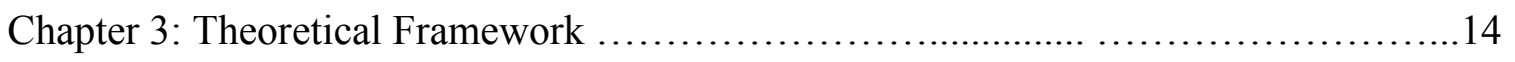

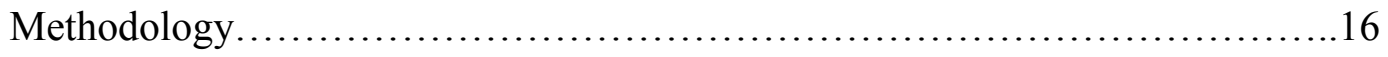

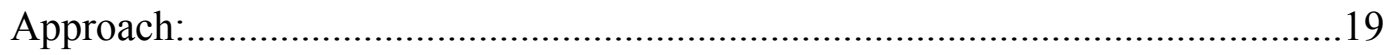

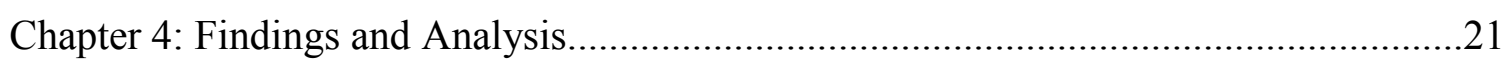

Experiences of Systematic Oppression.....................................................22

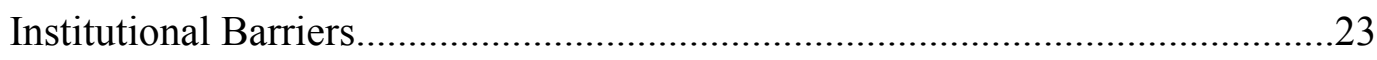

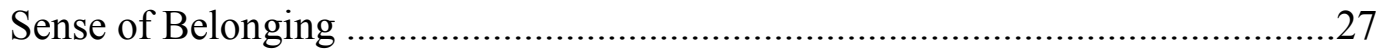

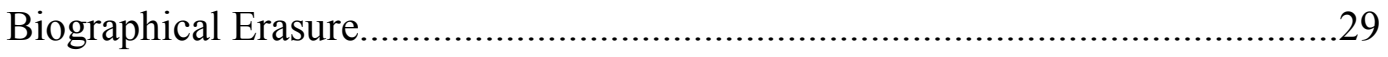

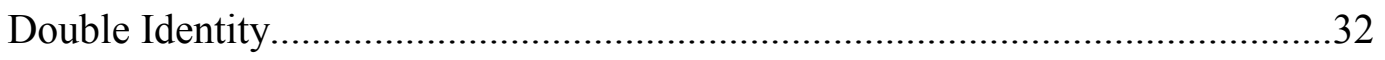

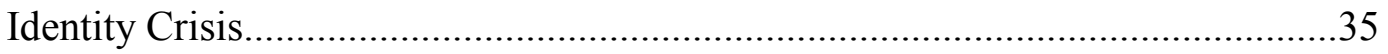

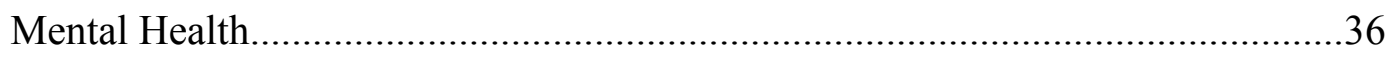

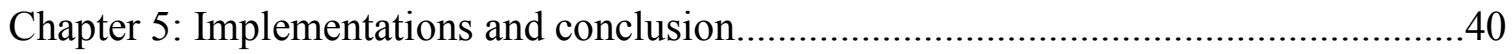

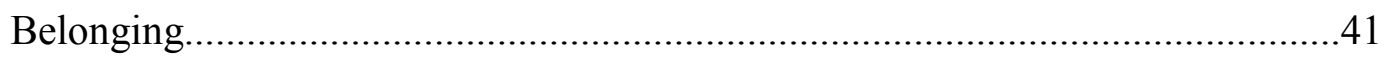

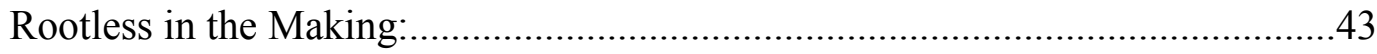

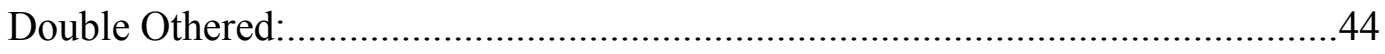


Silencing of Identity:.

Mental Health and the Afghan Community: A Message From Us to You........46

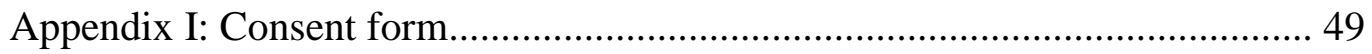

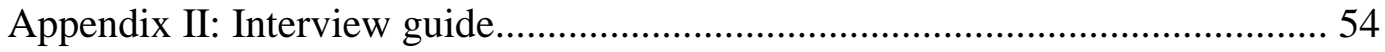

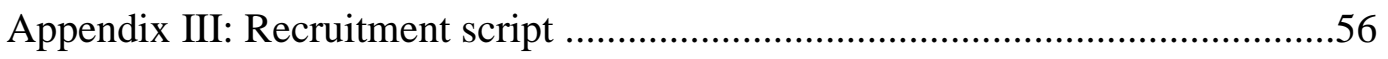

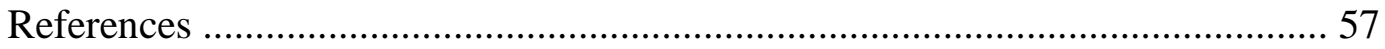




\section{Chapter 1: Introduction}

The purpose of this research is to shed light on the long-standing history of oppression faced by Afghan-Canadian young adults that remains relatively invisible within Canadian literature and society. This topic is important because Afghanistan is among the top ten source countries of immigration to Canada (Citizenship and Immigration Canada, 2004), yet little attention has been devoted to the lived experiences within Afghan diaspora (Sadat, 2008; Soroor \& Popal 2005; Quirke, 2014). Further, I am especially interested in this topic because, as a member of the Afghan diaspora growing up in Canada, I have experienced moments of invisibility and discrimination; moments that were incomprehensible given my primary identity and experiences. Consequently, this paper explores the mental health experiences of the first generation AfghanCanadians to center their experiences and feelings of belonging/not belonging in a Canadian post-secondary setting, and/or experiences of discrimination and marginalization. Moreover this research explores how these experiences impact one's mental health.

This paper has the potential to contribute to anti-oppressive practice as it sheds light on Canada's subtle and non-subtle ways of colonizing, racializing, marginalizing, silencing, and othering non-white bodies. Furthermore, this paper presents counter stories of Canadian experiences. These stories of survival are essential in addressing broader questions of social oppression, structural racism, domination, and marginalization of immigrant bodies (Sefa, 2007) and debunks the myth of Canada being a multicultural, anti-racist country. Furthermore, this paper is used as a platform for stories that have been and continue to be silenced. 


\section{Chapter 2: Literature Review}

\section{Afghanistan: A Wounded Country:}

For more than two decades beginning in 1979, Afghanistan faced a series of wars including an invasion by the former Soviet Union (1979-1989) and a second invasion by the United State of America and its allies (2001-present). Afghanistan and its people have experienced deep wounds, physically, emotionally, spiritually and otherwise (Dossa, 2008). As a consequence of war, 1.5 million people have died; $60 \%$ of children have lost their primary caregivers and 39\% have lost their homes (Chotani, Khan, \& Laaser, 2003). Afghanistan has an approximate population of 25 million people (WHO, 2006); the life expectancy for males is 41.9 years, and 43.4 for females (WHO, 2004). As such, $43 \%$ of the population is under the age of 15 and only $5 \%$ is over the age of 60 (WHO, 2006). Given this, it is no surprise that over $50 \%$ of women and children suffer from emotional distress including anxiety, depression, post-traumatic stress disorder, and schizophrenia (Azimi, 2004).

Despite the emotional and psychological needs of the population, there is only one, 60 bed mental health hospital located in the capital city resulting in 0.24 beds per 100,000 (WHO, 2006). Day treatment, impacts 8 users per 100,000 people, and five community-based inpatient clinics contribute for a total of 0.28 beds per 100,000 people (WHO 2006). The cost of antipsychotic medication is six Afghanis (the currency in Afghanistan), which is $12 \%$ of the average daily wage and the cost of antidepressant medication is eight Afghanis or $16 \%$ of the daily wage (WHO, 2006). More importantly, there are only two psychiatrists in the country (neither of which works in the mental health sector), 37 nurses without specialization in mental health, and 43 other mental 
health workers. Indeed, mental health services available are extremely limited for individuals requiring mental health support in Afghanistan.

\section{The Reason for Migration:}

As living became impossible in Afghanistan, Afghans fled their homeland and sought refuge in neighboring countries (Iran, Pakistan, and India) and then immigrated to the West (Quirke, 2014). Afghans currently represent the largest refugee group worldwide with 6 million displaced Afghans scattered across Europe and North America (Chotani et al., 2003; Dossa, 2008). The Afghan population in Toronto is approximately 60,000; this is a growing population as Canada accepts 1,000 new Afghans each year (Soroor \& Popoal, 2005). Furthermore, The Afghan population in Toronto is youthful as over 70\% of the Afghan population in Toronto have been in Canada for less than ten years and more than half are under the age of 25 (Quirke, 2011).

The challenges faced by Afghan youth are significant as their development and experiences are disrupted by displacement resulting from forced migration and separation from family and friends (Quike, 2014). Furthermore, these young Afghans have to take on responsibilities beyond their years, acting as the breadwinners of the family and as the primary caregiver of younger siblings and disabled, traumatized parents or parents who do not speak English or French and are too old to assimilate within the culture (Hart, 2008; Mann, 2008).

Although, there is a lack of literature about Afghan immigrant youth in the Canadian context, in the little literature available researchers have found that Afghan youth go through significant stress, as they, for the second time, have to navigate to a 
new school system. Moreover, Afghan youth cannot rely on financial or educational support from their parents. Furthermore, they may not be able to share emotional, educational, and financial distress with parents who may be equally frustrated with the system and dealing with their own financial challenges (Khanlou et al., 2008; Quirke, 2014; Suroor \& Popal, 2005,). They must also navigate the conflicting Afghan/family values, and the peer/Canadian values to fit in the school system and navigate Canadian society (Quirke, 2014). In addition to facing pre-migration trauma and post-migration settlement challenges, Afghan youth also encounter prejudice, discrimination, and bullying (Khanlou et al., 2008; Soroor \& Popal, 2005) that results in unforeseen mental health needs and contributes to the high rates of school dropout, depression, anxiety, substance use, and suicide (Soroor \& Popal, 2005). These concerns are addressed below.

\section{Prejudice and Discrimination:}

Prejudice is holding negative attitudes towards a group or its members (Kassin, Fein, Markus, \& Burke, 2013). While prejudice is concerned with negative feelings towards a group discrimination is associated with negative behaviors towards members of a group (Kassin, Fein, Markus, \& Burke, 2013). Furthermore, discrimination is the conscious and sub-conscious interpersonal interactions between individuals and the systemic practices of institutions (Edge \& Newbold, 2012). While prejudice can be seen as any judgments, discrimination is the actions that create and reinforce oppressive conditions that marginalize, and/or restrain the lives of those discriminated against (Dossa, 2008; Edge \& Newbold, 2012; Reitmanova \& Gustafson, 2009). These negative beliefs and attitudes about out-groups may lead individuals to categorize and reject 
groups of people, resulting in social inequity and limited opportunities and rights (Romero \& Roberts, 1998).

Although, there is limited work examining discriminatory experiences of Afghan youth and cultural identity in Canada (Khanlou et al., 2008), in the literature available, researchers have acknowledged discrimination and social exclusion to be an increasing component of daily life for many minority, ethnic youths (Anisef \& Kilbride, 2003; Galabuzi 2002; Shakya, Khanlou, \& Gonsalves, 2010). In a qualitative study examining discriminatory experiences of Afghan youth, all youths reported negative discriminatory teacher and peer interactions (Khanlou et al., 2008). The youths particularly discussed experiencing prejudice and discrimination due to how media portrays their country and their status as Muslims (Khanlou el at., 2008; Quirke, 2014). The youths also reported being discriminated against by teachers who associated their problems with their culture and religion.

As a result of such discriminatory experiences, students covertly excluded themselves from certain spaces. Some youths in this study reported feeling unwanted in academic environments (Khanlou et al., 2008; Sorror \& Popal, 2005). Evidence suggests that most discriminatory acts in Canada are subtle including being dismissed, excluded and/or treated unfairly (Dosa, 2008). These discriminatory and prejudicial experiences impacted the youth's expressions of cultural identity and resulted in intentionally silencing their cultural, and religious identity as they feared disclosure would bring further discrimination (Khanlou et al., 2008). Other participants talked about adopting the "Canadian" ways of being and knowing to "fit in" yet still experienced discrimination from teachers and peers. These youths spoke about how constant suppression of their 
cultural identity as a result of the fear of discrimination had taken a toll on their energy both physically and mentally (Khanlou et al., 2008). Altogether, prejudicial and discriminatory treatment within the media, school, and other settings inhibits the youth's sense of belonging.

\section{Sense of Belonging:}

Bouwsema, and Collier (1992) defined sense of belonging as "the experience of personal involvement in a system or environment so that persons feel themselves to be an integral part of that system or environment" (p. 173). Despite growing awareness that a low sense of belonging is a key determinant of mental and physical health there is limited research on the unique experiences of immigrant populations that may experience this within their host country as a result of multiple intersecting forms of discrimination (Edge \& Newbold, 2013; Shakya et al., 2010). It is only recently that researchers started exploring the relationship between sense of belonging and its relationship with mental health among immigrant populations (Agyekum \& Newbold, 2016). Research in these areas found that populations that have a positive sense of belonging in the host country are more likely to have better mental health than those that rate their sense of belonging negatively (Agyekum \& Newbold, 2016). A recent study in Ontario found that immigrants are more likely to rate their sense of belonging lower than the Canadian-born population and their mental health is consequently poorer than the Canadian-born population (Gallina \& Williams, 2014). This is interesting given the "healthy immigrant effect" whereby the mental health status of immigrants at the time of arrival is better than the Canadian-born population. However, the immigrant's mental health deteriorates with 
continuing years of residing in Canada (Agyekum \& Newbold, 2016; Dossa, 2008; Xu \& McDonald, 2010). Similarly, research demonstrates that he stronger the self-perceived sense of belonging one has to an institution, the greater the likelihood of that individual's success (Stebleton, Soria, Huesman, \& Torress, 2014). In North America, attending postsecondary education is important as it offers the possibility of financial wellbeing. For immigrant students, attending post-secondary education means achieving success, respect and a life that their parents envisioned for them (Suarez-Orozco, Suarez-Orozco, \& Todorova, 2008). However, immigrants go through a higher degree of stress and pressure in post-secondary settings as a consequence of their socioeconomic status, social support, and parental support/expectations that in turn impacts their achievement (Abada \& Tenkorang, 2009; Conway, 2009).

Additionally, immigrant, post-secondary students consistently have to navigate the values of their native culture and the host country (Calderwood, Harper, Ball, \& Liang, 2009), including living and navigating multiple identities and changing these identities to be accepted in different settings (Guo \& Jamal, 2007). Despite facing discrimination alongside value and identity conflicts, that can affect academic achievement and mental health, their needs often go unmet (Kilbride \& D'Arcangelo, 2002). Thus, it is not surprising that immigrant students feel a lower sense of belonging in academic settings when compared to their fellow students from the dominant culture (Stebleton et al., 2014).

In other words, when immigrant students' social and cultural practices and knowledge are undervalued, they feel isolated, alienated and become inclined to withdraw from academic settings. Most of the immigrant students who do stay in such 
settings are covertly forced to silence their culture of identity and assimilate to the dominant Canadian ways of being and knowing. This process is best captured by the term biographical erasure. Gastaldo (2014) describes biographical erasure as the complex involvement of Canada in disclosing lack of interest, ignorance, indifference, and at times prejudice against the ways of being, knowing, acting, talking, and thinking, of the immigrant population (p. 62). Some Afghan students in the Khanlou et al. (2008) study talked about their experiences of biographical erasure when they spoke of the need to hide their identity to be accepted and to avoid discrimination by their peers and teachers.

Since the vast majority of Afghans in Canada are first-generation immigrants, they make it through school by silencing their cultural and religious identity and by assimilating into Canadian culture in order to fit in. If they do not, then they have a much higher likelihood of discontinuing academic studies. In a study done on Afghan youth by Surroor and Poppal (2005), approximately 31\% of Afghan youth reported facing difficulties adjusting to the school system, $75 \%$ of Afghan youth reported experiences of racism and Islamophobia, $40 \%$ reported being suspended and/or expelled, $30 \%$ reported skipping classes, $23 \%$ reported to have failed in school, and $20 \%$ refused to go to school (Suroor \& Poppal, 2005). In the same study, students were asked to name barriers to succeeding at school. The identified barriers included language problems, unsupportive and ineffective teachers, lack of confidence, financial problems, managing work and school, stress, drugs, racism, discrimination, bullying and family problems (Suroor \& Poppal, 2005). In this study, it is evident that experiences of discrimination and lack of support are significantly related to the sense of not belonging in school and the success rate of completing school. 
The data above is consistent with literature that suggests school success is related to feeling wanted and safe within the school environment (Stebleton et al., 2014; Suroor \& Poppal, 2005). These results are significant and pose a threat not only to the school success rate, but also the mental health of Afghan youth living in Toronto. As there is a strong correlation between a sense of belonging and mental health and even more importantly, associations between a sense of belonging in school and one's level of depression and stress, (Meeuwisse, Severiens, \& Born, 2010; Stebleton et al., 2014). As

previously stated, the Afghan youth community's experiences of prejudice and discrimination are barriers to maintaining a positive sense of place within the school system leading to poorer mental wellness.

\section{Mental Health of the Immigrant Population:}

According to WHO (2016), there is no health without mental health; therefore "health" can be defined as the complete state of mental, social and physical well-being, not merely the absence of disease (WHO, 2016). Mental health is "a state of well-being, in which the individual realized his or her abilities, can cope with the normal stresses of life, can work productively \& fruitfully, and is able to make a contribution to his or her community" (WHO 2016, p. 1). Despite a lack of research on the mental health needs of Afghan youth, we will look first at what does exist addressing the mental health needs of the immigrant population in Toronto. Canadian immigrants start with a health advantage because they go through health screening to ensure good health before being accepted to the host country. However, in Canada, the health of the immigrant population deteriorates with the length of their residency (Agyekum \& Newbold, 2016; Edge \& Newbold, 2013). 
The decline in immigrants' physical and mental health suggests that there are factors within the host society that contribute to this concern (Agyekum \& Newbold, 2016; Edge \& Newbold, 2013; Quirke, 2014). These factors include the acculturation process, barriers receiving health care services due to difficulties in language, education and income, cultural differences, exposure to discrimination, racism, and a lack of support (Agyekum \& Newbold, 2016; Edge \& Newbold, 2013; Khanlou et al. 2008; Quirke, 2014; Shakya et al., 2010; Sorror \& Popal, 2005).

Canada is portrayed as a country that is welcoming, supportive, non-racist and that guarantees justice, freedom and equal rights for all of its members (Reitmanova \& Gustafson, 2009). However, it's been demonstrated that immigrants have little control over how they are received into society and how they are treated. These findings especially apply to visible minority immigrants. A study done by Reitmanova \& Gustafson (2009) found that immigrants experience mental health deterioration, as they do not have significant social support from their immediate and extended families and friends who are physically far away. Moreover, this is exasperated by financial difficulties, ethnic and religious discrimination at work and school, not having the freedom to practice one's religious beliefs and cultural traditions, school curriculum related issues, and a lack of culturally and linguistically appropriate mental health services. This study acknowledges that mental health deterioration is the outcome of a prejudicial, discriminatory, racist, and uncaring society and advocates for a collaborative partnership between government policy makers, local community health services, and immigrant communities to provide better health care for the immigrant population. 


\section{Soroor \& Popal, (2005) Article; Mental Health of Afghan Youth:}

The mental health experiences of Afghan immigrant youth are understudied and consequently it is difficult to identify the mental health needs of immigrant Afghan youth in Toronto. Thus far, there is only one empirical research on the mental health experiences of Afghan youth in Toronto. The motivation behind this research study was the increasing number of youth suicides in the Afghan community. This study was conducted by Soroor and Popal (2005); the study highlights unique challenges faced by Afghan youth and the coping strategies they use to address these challenges. To give a broader picture of the needs and concerns of the Afghan community and Afghan youth, the study involved 211 Afghan youth, parents of these youth, and key service providers who are involved in helping the Afghan community (Soroor \& Popal, 2005). The youth were recruited through outreach in several high schools in Toronto, a large number of the participants coming from, Scarlett Heights Entrepreneurial Academy, Marc Garneau Secondary School, A.Y. Jackson Secondary School, Cedarbrea Collegiate and Weston Collegiate. Principles, teachers and school social service workers were contacted to encourage Afghan youth in their school to take part in this research. In addition to that the Tar-O-Taaza radio program, the Sabawoon Afghan Family Education and Counselling Centre, Afghan cultural events, and the Afghan woman's organization extended recruitment invitations to their members and contacts. Parents were recruited through word of mouth and snowballing method. In addition to that, service providers (front line workers who were in regular contact with Afghan youth) were contacted through letter and phone calls and encouraged to complete the online service provider questionnaire. Over the course of the research, three types of data were collected: 
individual interviews, focus groups and online. However, due to the language barriers, all data collection instruments for parents and youth were translated into Pashto and Dari; however the online youth questionnaire was only available in English. In total 211 youth questionnaires were completed and analyzed, the parent focus group consisted of a total of 82 parents, three different focus groups session were conducted, and 16-service provider completed the compressive questionnaire (Soroor \& Popal, 2005, P. 25-27).

\section{Youth's Self-Report:}

The findings of the Soroor and Popal (2005) study on the mental health experiences of Afghan young people are concerning. The study reports that nearly onequarter of the Afghan youth reported having thoughts of suicide. One-third of Afghan youth suffer from symptoms of anxiety. One in ten reported symptoms of post-traumatic stress disorder. One in ten reported symptoms of an eating disorder. Nine in ten reported having exposure to violence. Two-thirds of Afghan youth reported not finding the mental health help they needed. Sixteen percent of Afghan youth reported having either hurt themselves or have attempted suicide. Moreover, Sixteen percent reported having problems with anger and frequently experience aggression. Fourteen percent reported feeling isolated and lonely and thirty one percent reported experiencing war trauma. Sadly, only nine percent reported accessing mental health services (Soroor \& Popal, 2005, pp.58-60). There are several barriers that prevent Afghan youth from accessing mental health services including a lack of knowledge about mental health, language barriers, the stigma of mental health concerns, no access to appropriate services, fear of 
being judged by the community and a lack of information available/accessible in the community about mental health (Quirke, 2014; Soroor \& Popal, 2005).

\section{Service Provider's Reports:}

The reports of service providers were also concerning (Soroor \& Popal, 2005). Sixteen service providers participated in this study and the findings include: that service providers reported that $87.5 \%$ of the Afghan youth they work with suffer from low selfesteem; $87.5 \%$ war trauma; $81 \%$ suffer from post-traumatic stress disorder; $75 \%$ suffer from drug abuse;68\% demonstrated aggressive behavior; $62 \%$ suffer from anxiety; $50 \%$ suffer from depression; $50 \%$ are victims of bullying; $50 \%$ are victims of assault; $43 \%$ have suicidal ideation; $37.5 \%$ lack social skills; $25 \%$ are having spiritual issues; $25 \%$ are victims of theft; $18.8 \%$ attempted suicide; $18.8 \%$ experience psychosis and $12.5 \%$ have eating disorders (Soroor \& Popal, 2005, pp. 71-73). As such, it is not shocking that so many Afghan youths are facing difficulties in assimilating. It is not hard to grasp how a youth traumatized by war and having been a refugee at some point, suffers from anxiety and/or depression, or other mental health concerns and then encounters discrimination and racism, would have difficulty succeeding at school (Soroor \& Popal, 2005).

\section{Highlights and Limitations:}

The above literature review highlights that there is a lack of mental health services geared towards Afghan youth, adults, and families, specifically culturally and linguistically appropriate mental health services. There is a great need for funding to provide services and educate the Afghan community about mental health concerns and of 
available services. There needs to be more responsibility placed on the school system to recognize and intervene in bullying, and on racism and discrimination to ensure a more inclusive environment for all immigrant youth.

\section{Limitations:}

As stated above, there is a lack of research on the mental health experiences of Afghan youth. The limited research available focuses on the mental health of the "at risk" youth who are in high school and immigrant youth in general. There is no research available on the mental health experiences of Afghan youth who are attending postsecondary institutions, their challenges, and coping mechanism. Therefore, this major research paper, explores the mental health experiences of Afghan post-secondary students in Toronto. Specifically, this paper seeks to hear from first generation Afghan-Canadians about their experiences and feelings of belonging/not belonging in a Canadian postsecondary setting, and/or experiences of discrimination and marginalization and how these experiences impact their mental health.

\section{Chapter 3: Theoretical framework}

Critical Race Theory has guided the theoretical framework of this Major Research Paper. This framework is appropriate for this research as it examines issues of power, race, gender and class, among other social inequalities that implicate educational institutions (Delgado \& Stefancic, 2012). Furthermore, CRT is concerned and committed to uncovering institutional constraints put on certain bodies and certain communities based on their race. This includes uncovering of how racism directly shapes legal systems, how one thinks of one's self, family, ethnicity, religion, and situation in respect 
to systems built on racist notions and how racial categorization, prejudice and discrimination directly results in psychological, sociological and political deterioration of the receiving group. In doing so, CRT is committed to asking critical questions about the notions of equity and diversity along racial lines and hierarchies in hopes of making changes and transforming the detrimental social situations of people of colour.

According to Parker and Lynn (2012), there are three basic foundations of Critical Race Theory. The first foundation is to bring forth subjugated experiences, and to create a platform for experiences deemed unimportant and silenced in mainstream society; in other words, discriminatory experiences from the perspective of the people of colour. These stories are gathered during qualitative interviews; common themes and stories can be put together to illuminate discriminatory practices. Such stories provide a counter narrative of people of colour and challenge the dominant discourses of equality and equity that serve to continue suppressing people of colour in Canadian society (Solorzani \& Yosso, 2002). In this case, institutional discrimination is examined, and the subtle and unconscious racist policies and procedures established in higher education. These include hiring decisions, scholarships, time deadlines, lack of accommodations and other practices that are designed for the failure of 'the other' (Richard, 1982).

The second foundation as CRT argues, is the eradication of racial subjugation while recognizing that race is the product of social thought and relations and thus, a social construct (Parker \& Lynn, 2012). Race is fluid, inherent and objective in the eye of the discriminator; it's shaped by political and structural systems and informed by individual lived experiences (Creswell 2007, p, 28). Due to political pressures and media reporting, certain races become essentialized to a social construction. When convenient, 
they become fixated into negative stereotypical notions that are unidimensional. For example, in one age, middle-eastern people were fixated as exotic, fetishized figures wearing veils; whereas in another era they have become, the oppressed, crazy terrorists set on the destruction of America and obsessed with killing the innocents (Delgado \& Stefancic, 2012). As such, the views on the race of particular peoples of color is always changing through political pressures. Currently, Afghan men are viewed as terrorists and women as oppressed. I cannot count the number of times I am asked, "How do you feel about being from a country like Afghanistan", "You are not a typical Afghanistani woman" and "aren't you forced to cover your head?" This begs the question, 'how can one be so limited and minimized in one's behaviors, abilities, and power in the eyes of the beholder?'

Finally, the third foundation of CRT addresses race and intersectionalities such as gender, class, ability etc. (Parker \& Lynn, 2012). As such, in these cases, there are intersecting points of power, privilege, and/or oppression within one's identity larger than race. Intersectionality forces one to consider identity through a wider interlocking lens.

In the case of an immigrant Afghan family, race does not exist outside of class and class does not exist outside of race; they all intersect, affecting the family on a psychological, physical, and social level. In using CRT, this research is committed to race and racism in all respects. The research must present transformative solutions to the subjugated experiences of immigrants within our society and in this case, educational institutions. Therefore, using CRT, this research commits to hearing how Afghan students experience discrimination in secondary institutions. Another reason CRT was chosen for this research is that it deems storytelling as essential to analyzing myths and stereotypes 
about minority groups. Furthermore, storytelling will be used to restore power to the oppressed and vocalize and understand how one comes to be oppressed and use this understanding to stop self-blame and mental violence. In providing a platform for such stories, it is intended that shared experiences, including living in silence resulting in selfblame and further negative experiences, will be revealed. In talking about and uncovering these stories these oppressions can be named and addressed in the hope of combating them.

\section{Methodology}

\section{Data Collection:}

The first step to any study is review of existing literature that can inform the study and data collection. In considering the literature thus far, I used various search strategies and collected multiple articles and books from search engines and database. Key terms including "Afghan diaspora" "Afghan Immigrants" Afghan immigrants and mental health" "Immigrants and mental health" "Afghan-Canadian" "Afghan post-secondary students" "Post-secondary and mental health" "Afghan history" "immigration policies" "discriminations and racism in Canada" among others were used. It was an ongoing challenge to find data directly related to this topic. Thus, despite the absence of literature on this subject, some research regarding immigration issues and first generation student experiences in post-secondary institutions was located.

After obtaining approval for this study from Ryerson University's Research Ethics Board (REB), I reached out to Ryerson University’s Afghan Student Association, who then extended recruitment invitations to their members and contacts. I also asked my 
peers and professors at Ryerson to disseminate my recruitment flyer to their contacts. Interested participants reached by the 'snowball method' were provided with both my email address and phone number and were able to communicate with me through their preferred method. This provided an initial consent by participants to share contact information with me and for them to ask any further questions. Written consent followed upon agreement to participate in an interview. Due to the Research Ethic Board's concerns, I did not have permission to reach out and recruit directly from other postsecondary intuitions in Toronto, however, if a student from another post-secondary institution contacted me I included them in the study.

Seven potential participants approached me. However, I was limited to recruiting a maximum of three participants; I chose the first three participants to contact me. This was due to the nature of the project's size and time limitations. Three post-secondary students were recruited; all participants were born in Afghanistan and had lived in an intermediate country (in this case India and Pakistan) before immigrating to Canada. This finding is typical as many Afghans seeking refuge had to flee to a third country. Participants spoke at least three languages due to living and participating in either courses or school in the intermediate country. All participants had some language exposure to English before immigrating to Canada. Participants' ages ranged from the mid 20's to early 30's. All participants came to Canada as landed immigrates. All participants were single. Although not intended, participants were from three different universities in Toronto; Ryerson University, York University and the University of Toronto. Two participants were involved in postgraduate studies, while one was in their final year of a 
bachelor's degree. All participants spoke about negative mental health experiences, but none labeled their experiences as an illness.

Because of the goal of this qualitative research project, I make no claims of the representativeness of the sample size or generalizability of the findings; rather I do my best to bring forth the essence of the stories being shared. A small sample size is not uncommon in qualitative studies, as researchers are interested in capturing the rich and in-depth experiences of lived experience. In fact, Polkinghorne (1989) suggests that researchers should interview 5-25 participants who have experienced a phenomenon. Due to time constraints, three participants were interviewed. I am very confident that the information gleaned provides the essence of the participants' experiences.

To maintain confidentiality, all the interviews took place in a private study room at Ryerson University. All signed consent forms, audio-recorded interviews, interview transcriptions, and contact information (names, e-mails, and phone numbers) collected were placed in a safe space that was only accessible by the researcher. Participant's email and phone number were collected for the sole purpose of facilitating interview arrangement and correspondence with participants during the research process. The information was kept confidential and securely stored electronically with password protection, encrypted USB and deleted once the data had been coded and analyzed. None of the personal information will be used in the research publication. Participants' identities are protected, as pseudonyms replace their names. Participation in this study was completely voluntary. Participants could choose whether to be in this study or not. Participants were informed they could skip any questions and choose to stop participating, or may also choose not to have their data included in the study before the 
process of data analysis began. They were informed that their choice of whether or not to participate would not influence any future relations with Ryerson University or the investigator (Naro Hussaini) involved in the research.

Based on the findings, I developed recommendations for academic institutions and the Afghan community. I believe the recommendations are important for policy makers, service providers, and Afghan students and parents. This study identifies important gaps in the Afghan-Canadian community and recommends further future indepth research to be conducted in this community.

\section{Approach:}

In carrying out this research topic, I used qualitative research as the intention is to capture the essence of the mental health experiences of first generation Afghan postsecondary students in Toronto, Canada. This topic requires examining sensitive nuances and participating in dialogues that could only be made possible through a qualitative approach. The research uses a phenomenological analysis as it centers on the participants experiences and feelings of belonging/not belonging in a Canadian post-secondary setting, and their experiences of discrimination and marginalization and how these experiences impacted their mental health. The purpose of using a phenomenological study is to bring forth the meaning and essence of lived experiences of this phenomenon. In doing so, I have focused on the common themes between all participants when describing the experiences of the phenomenon. Data is analyzed using the procedures of Van Kaam (1966) and Colaizzi (1978), that consists of identifying a phenomenon to study, interviewing and collecting data from several people who have the lived experience of the phenomenon, then analyzing the data by highlighting significant 
statements, coding information, and dividing statements into themes (Moustakas, 1995).

Using these common themes, I then developed a "textual description" of the participants' experiences and description of the context that influences the phenomenon and how it was experienced. This is followed by a "structural description" of the experience, including how the phenomenon was experienced, what the conditions were under which the phenomenon was experienced and what was the cause/effect of the experience in hopes of conveying the overall essence of the experience to the readers (Moustakas, 1995).

Over the course of the research, two types of data were collected: field notes and interviews. Field notes were collected in the form of handwritten notes during and after the interviews; field notes consisted of short phrases that stood out during the interview. A total of three in-person interviews were audio recorded using a handheld digital recorder. The audio-recordings allowed me to create an accurate transcription of the interviews. All identifiable data such as names of the participants were removed from the transcripts. The interviews were 120-200 minutes long and transcribed into 85 , single spaced pages. Each transcript was read 3-5 times, and codes were manually recorded. Originally 150 codes were recorded and divided into three major themes and subthemes.

\section{Chapter 4: Finding/Analysis}

The following paragraphs discuss findings of the research. Three major themes and four subthemes emerged from the subset of the data on the participants' experiences of prejudice and discrimination in post-secondary institutions. The first theme is related to systematic oppression; this section also includes institutional barriers to higher success in post-secondary settings and how these obstacles lower one's sense of belonging. The 
second major theme is Biographical Erasure. This theme relates to the suppression of cultural and religious identity due to systematic and institutional oppression and according to the stories of our participants, leads to the creation of a double identity. Double identity is formed as a coping mechanism to navigate the system. Continuing social navigation and consistent changing of values can lead to the question of "who am I really?" This leads to the third major theme, which participants called "Identity crisis" leading to adverse mental health experiences.

\section{Theme 1: Experiences of systematic oppression:}

When interviewing participants, the first few questions were related to demographic information and everyday life. When asking participants about their daily duties, all three participants looked puzzled as they were sorting out all the responsibilities they had on a daily basis. Although, as an Afghan person and a postsecondary student, I had an idea of what responsibilities they might have, stories of the participants left me shocked. All three participants reported to have at least one full-time job while being enrolled in full-time school. Two out of the three participants said carrying at least two jobs, of which one was full time while being enrolled in full-time school.

Two out of the three participants discussed experiencing systematic oppression regarding time. For example, 22-year-old Ali (all names are pseudonyms) stated:

People need to understand the challenges of first generation Afghan students and that they are not just any first generation; being an Afghan they have gone through 30 years of war; their parents, their grandparents. So it all adds up as apposed to coming 
from a country that hasn't experienced similar incidents that the country of

Afghanistan has faced. Most of us have to provide for our families here and back home financially and medically, while we are in school. It's certainly not an easy path for us

He continued:

There were many times when I had to sacrifice school for work and work for school, so either way I lost something whether it be knowledge or work and many times I had to sacrifice knowledge because I had to pay to be within the system.

Ali has beautifully captured his experiences of systemic classism as he shared his experiences of having to sacrifice school for work to stay in school. During the interview, he also reported that the Ontario Student Assistance Program (OSAP) would not cover his finances due his income. This is not a new narrative to the Afghan community, as many Afghans have to work double shifts to not only provide for family members here but also back home. This speaks to the employment offered to immigrates, which is usually low paying and as a result, the immigrant body has to take extra shifts to cover their expenses. Zainab, a 27-year-old female, who currently works two full-time jobs, a part-time job and full-time school reports:

A typical day would look like waking up at four in the morning and getting home at twelve. Then on the bus like legitimately, as I'm reading my readings I would fall asleep. I don't regret it or anything and not feel bad because I do it just because family needs it.

When asked when she gets to rest? She reported: 
Seep is like a privilege, and I realized that [smile] when I started having my second job, and the third job kicked in, and I'm like that's it, because I think sleep, resting has become like a privileged thing, not everyone has access to it.

Both Ali and Zainab talked about experiencing systematic oppression in facing multiple barriers to maintain and achieve in school while having the familial responsibilities that are not addressed by Canadian institutions.

\section{Institutional Barriers to Higher Success in Post-Secondary Settings:}

In the previous section, systematic oppressions regarding managing work, school and family life was explored. In this section, institutional barriers to higher success in post-secondary settings are addressed. In Canada, specifically in the post-secondary institutions, we are all tied to time and deadlines. These timelines /deadlines are set up as a form of institutional barrier to those who have very limited time. In this case, for individuals like our participants who have more responsibilities than time, meeting deadlines can become a barrier to their success. When speaking about challenges in postsecondary institutions participants talked about "not being understood" by their professors. When asked what that looks or feel like, Zainab said:

Well, I can't give them any proof of where I am standing in life right now, like who do they want me to bring to prove it to them that you know I have three jobs. More specifically, participants talked about the bureaucracy and paperwork when asking for accommodation and how it adds another layer of stress on an individual level. Zainab continued: 
Like the bureaucracy of the paperwork, like you need to do this, you need to do that, itself, I think is too much for the students. To the point where you're like you know what just forget it, instead of like spending five, six, hours on that, I would rather get this assignment done and get that $\mathrm{C}$ instead of an $\mathrm{A}$.

Barriers to success did not just include managing school and work but also the emotional tragedies of the situation in Afghanistan, and lack of understanding of its impact on Afghan students in Canada. Zainab explained:

There's lack of understanding, for example, a neighbor was killed in a bombing in Afghanistan. It had a huge impact on me here; when I asked for accommodation, they said you need to provide documentation. How am I going to provide documentation for somebody back home and how it's affecting me in here?

While participants spoke directly about the impact of systemic and institutional oppression as forms of exclusion and barriers to higher education. They emphasized the importance of education as a means to secure employment; employment that can be achieved only with a high school diploma, an immigrant person has to have a higher education to obtain such work. As Ali stated:

When it was finally time for job seeking there was a sense of discrimination or a sense of non-acceptance. The fact that their parents (other students) or their connections were able to connect them to the right employer or job position. When I was expecting everyone to be almost in the same boat, I'm applying at the same time as them, and we just get chosen. But now, however, I was first generation student, my parents did not go to college or university. They did not have a highend job or a white-collar or blue-collar job in Canada. So now I felt the sense of 
direct discrimination in the sense that I have to work harder now to obtain the same job as someone with high school diploma.

Similarly, the third participant, referred to as Reza, who has multiple graduate degrees, reported that he decided to attend law school as a form of resisting systematic oppression. Reza stated

The reason I went to law school is because this profession is going to give me a level of knowledge and put me in a category that will be hard for me not to have good opportunities. The reason why I felt that I am going to achieve something much higher later was because I didn't feel I was given enough opportunity. Something that only required high school diploma, myself with master's degrees, I was having a hard time, and there was no objective reasoning given to me. It was just the idea that, in my mind, it played out like ...ok I am an immigrant, and so even with a master's degree I am having a hard time attaining employment in a field that people with high school diplomas are getting. So I felt, ok, I am not going to put myself in this position anymore. I am going to attain a position where I am going to dictate my own future and my own life, professionally.

While participants initially reported facing systematic oppression and institutional oppression, they all emphasized the importance of post-graduate education to resist job discrimination and compete in the job market. Job discrimination adds another layer of stress and further decreased sense of trust and belonging to the educational institutions. when talking about sense of distrust in the institutions and the systems Reza explained how job discrimination affects one's mental health. 
It starts affecting your mental health because you become hopeless; you are not going to believe in the system. That's one, so you are not going to believe that it's a fair, equitable system, we have an equity kind of eh, we have equity department in all sectors, which is kind of sad because they have to monitor if there is equity in the workplace or even in terms of hiring. But the way it affects individuals is, they feel like they have to do twice as much to achieve something someone would achieve with no effort just by virtue of who they are. They feel that way because there are a lot educated people who aren't able to get opportunities, simply because of who they are, and where they've come from. So it affects them; it affects them mentally because it gives them the idea that they are not treated as equals in this society, and it gives them the idea that their.... they might even start doubting themselves as to whether they want to be part of the society, right.

In order words, individuals in these circumstances start questioning if they belong; if they are really wanted and needed in the institutions. But being in these institutions plays a major role. Not giving up also plays a role because if one does give up and lose hope, then they start believing that they are at fault and that they did not "try hard enough." When one goes to pursue higher education, they observe inequality in class and often observe that they are the only Afghan/Arab person in their cohort. It is not just about race; rather systems that are oppressive, that make it difficult for some to have access to such spaces. All of our participants, expressed being humble for having the means to attend post-secondary education even though it is very difficult because they know most individuals in their community do not have access to schooling due to systematic oppression. 
Sense of Belonging:

The negative experiences participants face in post-secondary institutions impact their sense of belonging to the institutions. While all participants have lived most of their lives in Canada, all of them reported feeling 'low to no sense of belonging' in Canada and to their post-secondary institutions. Reza who has lived most of his life in Canada and has been through post-secondary institution several times describes assimilation as a way of finding acceptance:

You are accepted but how you are accepted and the level to how you are accepted depends on how much you can assimilate into the mainstream society, to their ways, or to everybody in general. So that includes social functions. If you are not, if you don't fit into that kind of way of life and you don't believe in being in certain functions or you don't believe in going out for you know for drunks or whatever, you don't believe in interacting in certain ways, then, you are going to limit yourself and the success you might have.

Reza believes, to be accepted, one must make some changes to their cultural and religious values and accept assimilation into the Canadian values. Although this might have been a coping mechanism for Reza, the other two participants report never finding their way to a sense of acceptance and belonging to their institutions. For example, Ali talks about his experience of not belonging being directly tied to issues of classism:

I feel like, and I'll give you a very specific example. Let's say you have a $\$ 200$ hold on your account. What the university does is they block your transcript; they block any means that is necessary. So I feel like university like, the major thing, they care 
about is money and if they get the money you're good and if they don't you're screwed. So I've never felt like I belong here at all because I would have to work while I was supposed to be in school, to pay for school and to stay in school.

Similarly, Zainab talks about her experiences of not belonging due to having too many responsibilities outside of school which prevented her from engaging in matters close to her heart and experiences of not belonging as a result of uncaring professors: Belonging to me would be attending class and listening to the prof, without having so much in my head. Cause sometimes when you're sitting there, trying to focus on the lecture, you have to deal with so many other stuff that's at home; I need to do this I need to do that, or like make sure my parents are okay, like stuff like that. So I think that kind of challenges the experience of belonging but yet at the same time I feel like school is more of a commodity when I look deep into it, where I'm just....like any other......like I'm a number where I just go there and pay them and then come out, and whether I do well or not it doesn't affect anybody except me.

Reza talked about his experiences of navigating the system while maintaining his Afghan values, yet assimilating to the Canadian ways of being and doing enough to feel accepted and belonged. All participants reported the consistent negative messages they were indirectly receiving about their culture that directly affected their sense of belonging.

\section{Theme 2: Biographical Erasure:}

Biographical erasure as mentioned in the literature review section refers to the consistent involvement of Canada in displaying a lack of interest, ignorance, indifference, 
and at times prejudice against the ways of being, knowing, acting, talking, and thinking of the immigrant population (p. 62). Biographical erasure is a theme that was consistently brought up in the stories of the participants. They explained their experiences of biographical erasure in the subtlest ways. For example, Zainab talked about an incident when she chose to disclose her ethic background during a presentation as a way to represent her country and was told by her professor "why did you disclose where you are from? Here we are all Canadians." The act of not allowing/ encouraging a student to state their ethnic background is in itself showing a lack of interest in that person's identity, even worse though, is telling them that since we live in Canada, we must all be Canadians. And if we do not follow the footsteps of what it means to be a Canadian then we are left out, as Reza illustrates:

The reason why we did things growing up here is because we had no other option; we didn't have space or groups. I didn't have a group of guys like myself, from Afghanistan, that could go and hang out somewhere and play cards. So I ended up doing was what everyone else did because everyone my age that I grew up with that's what they were doing. If I disengaged from them, I would be all by myself. Universities need to create an opportunity for everybody, so they have an outlet or opportunity to engage in things that relate to them or that they prefer. Or if they don't have it, they will go and engage in things that are not so natural and can't even share at home.

The creation of spaces that only allows one way of being and doing creates challenges for people to promote and grow their cultural values. In fact, not authorizing the creation of spaces that brings on other values is itself a form of biographical erasure, 
signaling that there's only one way of existence and that's the 'white way' of existence. When educational institutions do not allow spaces that promote diversity and difference, it results in erasing the uniqueness of cultures, stories, and struggles faced by the other, in this case, our participants. When asked what universities need to do to increase one's sense of belonging, all participants spoke to a need for the creation of platforms that are congruent with their stories, values, and believes. The following is what Zainab stated regarding what needs to be done:

Universities need to create a platform space for them, where they all come and share their stories, proudly, and this goes back to like you know, I come from this place; like I have these horrible or great or bad like experiences. Whatever it is, create a platform to talk about it. I probably have great stories to tell you, and I have horrible stories to tell you. And that, just that space can create a sense of belonging, like, people care about me and my experiences and want to hear it, you know?

Similarly, Reza expressed what he imagines universities could do to increase acceptance of cultural and religious experiences. He expressed that for him, academies would need to be more accepting and accommodating of different groups, for example, he stated:

Let's say there's community. If I have to use an example let's say the university has a group of students who wish to pray. What the university can do it is to accommodate them so they don't feel out of place. So I guess you can say accommodate different cultures. I think they already do that but maybe they could 
do more; maybe they could accommodate more facilities to certain groups, so they don't feel out of place, so they don't feel like they don't have any other options.

More importantly, participants talked about the outcomes of not creating spaces to accommodate the psychological challenges that arise from the structural forces of biographical erasure. Reza stated:

I think the way we react is because of how we are treated by the outside and so the structure outside is what creates what's on the inside. So when it comes to Afghans, we are very reactive and defensive. We don't do things; we don't create or perpetuate things, we only react to things that are done to us. I think it's the structure that exists outside that makes us feel unnatural because we feel like we don't want to change our ways just so we can fit into this society. So, the way I would say we can deal with that is accepting that it's ok to not fit in. Some of our values are ok; some are not great and yes we do away with them but there are a lot of good things too, so we don't need to do away with those good things. I feel like we are doing away with those good things too now. There are a lot of good values that we are letting go, and the good values are just, to name one is dignity and respect for each other. I am not going to say that I am making the right assessment; I think that people are a little too open now with the new ways of things; they don't really respect themselves or each other anymore. I notice people are trying harder now to be part of that mainstream now and if you are not part of that mainstream [then] you are behind in life, or you are totally backward thinking.

This example indicates the participant's experiences of structural biographical erasure, and how it can destroy culture and personal values. In this case, the 
"mainstream" ways of being (which has been identified as "Anglo-Saxon kind of Euro, Anglo way of life" by Reza) it's referred to as "White ways of being and doing" which has become the means to colonizing communities. Structural biographical erasure has left many youth and young adults feeling rootless and developing a "double" identity to navigate belonging resulting in identity crisis and double othering.

\section{Double Identity:}

Experiences of systematic oppression, institutional oppression, and biographical erasure have significant negative impacts on the lives of Afghan young adults. In navigating these negative experiences, many Afghan young adults have to develop double identities; an Afghan identity and a Canadian identity. The Afghan identity is the authentic identity that values Afghan and Muslim ways and epistemologies, while the Canadian identity is developed to blend in and navigate social systems. For example, Zakia in the following paragraph talks about the clash of values she faces in decision making linked to colonization:

I always feel like I have two personalities; like there is one that is like pure Afghan, and when I say pure Afghan I mean like believe in all those traditions. Like marriage, respecting your parents and like everything. I think those values are really beautiful, they're nice. But when we get critical and question those values, then that's when the Canadian identity kicks in and that's like oh no you're not supposed to be doing that. Like right now we're looking at the research for a class, where the parents or mothers who stayed home back in the day to look after the children vs. now where both parents are at work and kids are left with a stranger. 
So which one would you prefer? You know what I mean? So for me it would be like I'd rather stay with my kid, or have my husband stay with my kid, then [silence] just like, they just grow up fast, and you want to spend as much as time with them as possible. So that's when the Canadian identity kicks in and you get to judge if you share that and is like no you need to go out there and work-- you're a strong woman..this and that, so I kind of feel like there's backlash.

She continued:

They change you; you are not [pause] like they make those values so unfamiliar to you. So strange when it was, it used to be your own thing [pause] but now it's like, you fear to say it.

The negative experiences of discrimination and biographical erasure results in unfamiliarity, uncertainty and consistently have to navigate identity. These are processes of the colonization of the mind. While Zainab's experiences speak not just to immigration issues but also challenges specifically faced by an immigrant woman and her decisions relating to children raising. Immigrant women of color are often viewed as oppressed and voiceless by Western societies; this process further perpetuates and instills self-doubt and oppression. Zainab continued speaking of her experience of navigation and alertness.

When you are somewhere, within these two communities, like if you're faced with a situation, you have to like think before you say something because you don't want to offend the other and the other could be an Afghan or Canadian.

Similarly, Reza talked about his experiences of the need to always be psychologically aware of how to behave and what to share in each setting and its impacts on one's identity: 
Our community faces the challenge of, or the difficulty or the problem of having to be two different people. That's the biggest thing in my opinion that we are forced to become different people towards different groups, that's not healthy; that's the number one issue that we face. You become one person at home and another person outside, and that's not a healthy thing, that creates mental health issues because you then start to create two personalities. When you have to create two personalities, and I don't mean acting appropriate or inappropriate, in different environments because that's normal. I am talking about two personalities, and that exist in our community: it has existed for a while. That's one of the root causes of these issues in my opinion because it's not healthy to suppress your feelings in one setting: and then bring it out in another setting you got to be able to express yourself. That in itself creates a mental problem because you are now hiding who you are as a person.

The creation of double-identity as a course of navigation leads to letting go and holding on to the Afghan and Canadian values and performing them in different settings, with different communities. Despite the pressure to perform a certain way and the consistent challenges my participants faced, they all strived to survive and continued education as a form of resistance. In the midst of all this, the participants expressed experiences of rootlessness and identity crisis.

\section{Theme 3: Identity Crisis:}

Accounts of double identity contribute to experiences of uncertainty and confusion in one's sense of self, values, beliefs, and identity. As stated previously, all participants disclosed the necessity of navigating between two identities as a coping 
mechanism in the educational institutions and the society as a whole. Participants talked about experiencing identity crisis when they are faced with discrimination even after they establish these mechanisms. Reza talked about his experiences of identity crisis when he first realized that, the number of years he resided in Canada or how much he identified with the Canadian system did not matter when it came to opportunities in his life. He explains his experience as such:

Like that situation where I feel like I am not given opportunities that's where I started to think, hold on, I have been here almost all of my life; I identify with it and yet I am not accepted. You get an identity crisis at that point. You start to wonder; what am I? Where do I fit?

He latter continued:

Afghans I believe do face identity crisis because they don't know where they belong anymore. Because the society they feel doesn't accept them and then they are no longer a part of where they came from because frankly, it doesn't exist anymore. I mean Afghanistan has become this thing where there's nothing to hold on and say this is what it means to be Afghan anymore because it's all over the place now.

All the participants expressed this narrative. Zainab expressed her experiences of identity crisis after years of performing. She said that she would not know how to perform if she was in a room with both groups. The following is her description of what identity crisis looks like:

You just, you don't fit in. When you go to like within the white society or the Canadian English speaking people, you don't fit in there either, and then if you go 
back home or within like we're talking about like Afghan, Afghans who they hold certain traditions dearly, then you're a stranger to them too, and that when you start questioning like who am I? Like, am I Canadian? Am I Afghan? Like where do I fit in? You know? You are just a lost soul.

It's important to state that I did not ask any questions about identity crisis during the interview. Moreover, all participants' stories lead to identity crisis when asked about belonging. It is an interesting finding as all participants disclosed experiencing "identity crisis" when asked about their sense of belonging to their campus. Research suggests that Identity crisis can have major negative mental health effects (Oppedal, Røysamb, \& Sam, 2004). Accordingly, participants were asked about mental health, a taboo subject in the Afghan community.

\section{Mental Health:}

Mental health is a difficult notion to wrap one's head around in Farsi. To Afghans, mental health is not just about mental well-being, it is a reflection of one's whole self. To the best of my knowledge, mental health translates in Farsi as "Terjubahaye aqli wa asabi" which translates in English as "Experiences of the brain and the mind". However, so far there is no specific language or terminology in Farsi that medicalize and pathologize mental health experiences. There are no such terms as depression, anxiety, panic attack, etc. Most mental health experiences are normalized and viewed as everyday human emotional experiences. The conflict arises when we live in a society that is deeply obsessed with medicalizing and pathologizing everyday emotional experiences of human beings. My last question for the participants was 'how 
do you define mental health in Farsi and how has the above experiences affected your mental health experiences?' Although it was very challenging for the participants to answer this question, it was surprising that their understanding of the term "mental health" was different from each other but was related to external factors instead of internalized inferiorities.

Zainab described mental health as "ehsasat e rouehe ki mehsoos mekuni az khater-e muskelat" which translates to "spiritual experiences as a result of difficulties/hardships faced" Similarly Reza described it as "mushlelat e darse o zindagi", which translates to "difficulties of studies and living" and Ali expressed it as "Wazyat e firkre", which translates into "states of mind."

The Question about mental health definition was striking to all three participants. All three participants made comments like "this is a difficult one" or "I need a moment to think about it" while participants were gathering their thoughts about mental health, they raised concerns about the stigma attached to mental health experiences in our community. This was brought forward in stating that there's lack of mental health conversation in the community, and that mental health is a "taboo" topic in the Afghan families and communities. To stay on topic, we redirected our attention to how attending postsecondary school has affected and continue to affect our participants' mental health experiences

Ali expressed:

I believe the restrictions and discriminatory actions that I faced at [silence] university, it stresses me out a lot and like it wasn't the body stress or anything; the body reacts to your mind, and if your mind is not at peace and is stressed out, [then] 
you can feel it in your body. Translating to your body, to your energy, to your behavior and the way you act and what you put out into the world."

Similarly, Zainab expressed:

I think there's that disconnect, like how much would they understand about your mental health state? I think the notion of accommodation should focus more on...it should be an equity thing, like based on your needs they should accommodate you, not based on what you're going to meet, like sometimes if you; a great example would be to be identified like there has to be a diagnosis. It's like okay she doesn't sleep, she feels sad, she's this, she's always crying, she's suicidal, and then, therefore, it makes her accommodatable. We need to get away from that. Cause it's-it's going to be its either long term or short term, something that may affect you within like a month, a year, or a day, and we need to recognize that so. Equity, I think based on their needs rather than having those setup standards already and telling them that you need to meet these needs to be needy."

It's not unusual for students from diverse backgrounds to feel like they do not fit in or are unstable in institutions and education that is catered only for the wealthy and the privileged. Anyone who does not belong to those categories understands that success in post-secondary is more difficult for them due to their social location. Although, there are systems, such as access center, mental health services, and counseling, in place to assist those experiencing difficulties in post secondary school; our participants states they never sought to receive services from these systems due to fear of being judged or misunderstood. Following is Ali's statement to why he did not seek help from the counseling center of Ryerson University: 
There are certain issues and topics I don't talk to certain individuals about. I'm just giving an example; it's because no matter what I tell them, how much I prove it to them, they're not going to understand me; they have not faced these issues; they did not come from the same country and situation as me; they're not going to understand. Such as coming from war back home or being a first generation student, or having to work full-time while in school while doing a million other things. I wouldn't trust the western system to know how I feel, know where I'm coming from. I believe they would just listen and not understand; maybe within the western system, if there were individuals that have been going through the same issues and problems in the past, [then] I would trust them more to listen to me and understand. Listening and providing advice is not enough, there needs to be three aspects; listening, understanding and then you give them possible solutions.

All participants stated that there needs to be diversity in mental health service providers. According to them, they do not see this being implemented at the institutional level. Thus, it makes them feel even further unwanted and not belonging in the institutions along with already not having enough time due to struggling with work, school, and family life. So we ask what needs to get done?

Ali replied:

Firstly institutions have to go back to their very core and their document and write down in their document; our focus is not on money, it's not on tuition. If I were to trust them with anything, the very first thing they have to think of is the fact these students' health and safety, then the money, then everything else. For example, individuals go through mental health issues because of their course load and the 
amount of work or what the system imposed on them. So for me to trust your institutions, feel belonging, and have positive mental health experiences, they have to display and show me that students' health and safety is no other than number one on their list.

From Zainab we hear that mental health accommodation should be accessible to all without documentation and diagnosis:

I think the notion of accommodation should focus more...it should be an equity thing, like based on your needs they should accommodate you, not how many times you have seen a psychiatrist or how many medications you are on. Because we don't do those things, so that means we will never be accommodated.

From Reza, we hear that institutions need to create opportunities for everybody, so they have an outlet and opportunity to engage in things that relate to them or that they prefer.

As mentioned, Afghan youth and young adults experience negative mental health due to external factors; including having too much responsibility and too little time, navigating the systems, not being able to share stressors with family members/parents as they are frustrated with the systems themselves, not reaching out to external mental health services due to the fear of being judged, misunderstood, and perhaps diagnosed for their emotional experiences. Although there are multiple suggestions given by our participants about what can be done for them to feel supported, the one that was highlighted most often was the need for diversity in the mental health service providers at the university level. This is an important finding as thus far, the literature suggests that immigrant students do not seek mental health services due to time constraints and the stigma of mental health. This research suggests that although time constraints and stigma 
maybe factors in not seeking mental health services, the primary factor is fear of being further discriminated against, judged, and providers internalizing mental health experiences rather than understanding the external stressors.

\section{Chapter 5: Implementations and Conclusion}

\section{Belonging:}

Findings of this study indicated that the three Afghan post-secondary students interviewed have a lower sense of belonging to their campus due to systematic oppression and institutional oppression. Systematic oppression is the systematic barriers put in place that make it challenging for the three Afghan students to be involved in meaningful activities on campus and create a sense of belonging. Systematic oppression includes poverty, family responsibilities, and discrimination. While institutional oppression involves, barriers set up by the post-secondary institutions that make it difficult for Afghan individuals to have access to certain spaces that may create a sense of belonging for them. Institutional barriers include lack of funding for groups that promote diversity and inclusion such as the Afghan Student Association, the lack of spaces that are inclusive and accessible to all individuals that promote and speak to all ways of being, doing and knowing. Institutional oppression also includes mental health service provision (which will be discussed below).

\section{Systematic Oppression:}

To begin with, despite arriving in Canada at early ages, the majority of the participants highlighted the difficulties they faced in managing school, work, and family life as a systematic barrier to their sense of belonging. Notably, there is a relationship 
between class and belonging, in the sense that two of the participants who reported coming from working class families, while in school reported a lower sense of belonging and talked about their struggles of living in a society that is obsessed with "equality" rather than "equity". Both of these participants shared the narrative of being the breadwinner of their families while being in school, and the struggle of qualifying for Ontario Student Assistance Program (OSAP) due to their income. Moreover, they are also the primary caregivers of their younger siblings and parents who do not speak English fluently. Responsibilities include taking the parents grocery shopping, assisting them to the medical appointments, etc. While the above findings are similar to the findings from previous studies that indicate Afghan young adults have to take on responsibilities beyond their years (Khanlou et al., 2008; Quirke, 2014; Suroor \& Popal, 2005), this study is different in the sense that it looks at systematic accessibility issues. This study indicates that Canada, as a nation has failed to provide accessible services to immigrant individuals. If there were services rendered that reached the needs of Afghan parents, such as employment for those who do not speak the English language, translators at the doctor's office, these would take some of the responsibilities off the shoulders of the young adults and give them to more time to engage in other meaningful activities. Furthermore, this study examines family income and the survival of the family. Afghan students do not just face barriers and accessibility issues from larger social systems but they also face institutional barriers from within the universities.

\section{Institutional Barriers:}

As indicated by all our participants, there is a need for creating spaces for Afghan individuals to come together and speak about day-to-day struggles and achievements. 
This is a new finding with regards to extant literature, specifically because every ethnic group has their own significant issues and struggles that they face in their communities, which could not be understood by individuals from other communities. All participants highlighted the importance of educational institutions creating platforms and spaces for Afghan students to come together and share their challenges and accomplishments. A space that is safe to talk about the struggles of the Afghan community, to talk about mental health, sexuality and gender, family responsibilities/issues and dating; all the topics that are taboo to talk about in Afghan families and will result in judgment if discussed in other spaces. Educational institutions and Afghan post-secondary students need to take on the responsibility of creating such spaces that bring like-minded young Afghans together and create a platform that will increase the sense of belonging of the students and decrease their stress and negative mental health experiences.

Similarly, all participants related a need to see diversity in the mental health service providers. All participants reported that they would not seek mental health services from their educational institutions due to the fear of being judged and misunderstood. For example, Zainab said she would not want her experience to become a "topic for the counselors to talk about after I leave the office". She said this when she explained that she does not expect the mental health providers to know about Afghan struggles and how they impact her mental health. Thus, there's a pressing need to hire individuals from diverse backgrounds; someone who has an understanding of the struggles of the immigrant communities and have lived it. This will help students feel sense of belonging to their campus and ask for help when needed. 
Rootless in the Making:

Findings of this study indicate that post-secondary institutions are deeply embedded in the implementation and the process of systematic prejudice and discrimination. These processes are shown in the absence of spaces, groups, and education that welcomes diversity. It's also shown in the limited diversity of mental health service providers, and in the absence of immigrant programs. The systematic oppression is further shown in bodies that no longer have a sense of belonging to their campus; bodies that are deemed weak for asking for accommodations and bodies that are gradually in the process of biographical erasure.

\section{Double Othered:}

The outcome of being double othered is that it hinders the process of settlement and adaptation. It hinders the process of coping with new academic challenges and dealing with new expectations at school and being accepted into new peer groups. Although, Afghan young adults are encouraged by their parents to stay connected with their religious and cultural values, they also want children to fit in the Canadian school system. In doing this, students are consistently faced with barriers as the Canadian school system engages in biographical erasure that requires young adults to let go of their traditional and religious knowledge and assimilate into the mainstream culture. The process of making the Canadian ways of being and knowing the norm causes these young adults to silence their cultural identity and increases their feelings of rootlessness, which often set them up for failure in school. According to the participants Afghan students 
will achieve greater success when their religions, culture, race, and ethnicity are reflected in their education experience.

Silencing of Identity:

Biographical erasure, takes places in many forms and shapes, in this case, biographical erasure, occurs in institutions as ways of creating acceptance. In other words, when the "other", when Afghan values and traditions are continuously seen as "abnormal" "backwards" and "unhealthy" by the dominant systems, they are sending a messaging to the "othered" body, suggesting that, they have to change to fit into the mainstream. They shall adapt and assimilate to Canadian ways of being and doing and no longer identify as an Afghan person or, at least, no longer identify as a "typical Afghan individual." What do we do to individuals when we signal these kinds of systematic prejudice and discrimination towards an ethnic group? We learn from the participants that the systems forced upon them create "double identity." One identity that comes out when at home and one when outside.

The strategy of creating a double identity works as a coping mechanism for some, while for others it becomes a way to dodge prejudice and discriminatory actions and to create a sense of belonging. The process of biographical erasure works in two ways; one is that it gives one the illusion that the more one assimilates to the Canadian ways of being, the higher the sense of belonging one will feel. The other is that the assimilation processes silences one's authentic self and cultural identity. This process becomes more painful when the individuals come to know that no amount of assimilation will lead to belonging. As one becomes rootless, neither belonging to their own community or to the Canadian community, it is madness in the making (In inserting the word mad, I do it in 
the spirit of reclaiming the word as critical mad scholars do; Poole, 2015).. Why does one have to pretend to have values that are not their own just to be accepted, and to be "normal"? What does this say about our educational institutions? What does this say about us as a nation and about our commitments to diversity? Mental Health and the Afghan Community: A Message From Us to You:

As I have mentioned previously, to our community, mental health relates to all aspects of life, yet what we come to learn from our participants is that we have repeatedly failed to connect to our family members, friends, and significant others when it comes to mental health. All our participants requested from the Afghan community, their families and friends, to be able to talk about mental health in an unthreatening way. They reported that there are significant changes in family dynamics in the Afghan community that "we no longer talk genuinely"; we no longer sit at the dinner table and ask "son, how was work/school today?" (Reza) "What are some difficulties you are facing?" (Reza) "We need to talk about ehsasat (emotions)" (Zainab).

These are all the ways we can talk about mental health. In this way, we have come to know that negative mental health experiences are as a result of living in an uncaring society; however, creating a strong and caring community could prevent negative mental health experiences. This section ends by asking everyone reading this paper, not to blame the individual for the structural barriers. Start the conversation about mental health: ask direct questions about emotions, love, gender, dating, and be there for each other as a community. All these are forms of active mental health talk and creating community.

The objective of this study was to explore the mental health experiences of first generation Afghan post-secondary students in Toronto Canada. This study created a 
platform to capture everyday experiences of Afghan post-secondary students' challenges and struggles in attending post-secondary institutions. The findings of this qualitative study present consistency with Khanlou, Koh, and Mills (2008) study as well as Soroor and Popal's (2005) study in regards to Afghan youths' explicit and implicit experiences of prejudice, discrimination, and systematic oppression. Quirke's (2011) study also confirms the findings of the present study in relation to silencing cultural identity as a form of coping mechanism and to avoid prejudicial and discriminatory actions in educational settings. Moreover, issues related to family responsibilities, financial responsibilities, and systematic oppression faced by Afghan students are in congruence with Khanlou, Koh, and Mills (2008) study, Quirke's (2014) study and Suroor \& Popal's (2005) study. This present study contributes to an improved understanding of the systems of oppression and institutional barriers that young Afghan adults face as students in postsecondary institutions and highlight adverse mental health implications (such as identity crisis) of on-going prejudice and discrimination. This oppression is faced in relation to the social location of Afghan young adults, including but not limited to their race, gender, class, ability, and religion. As a result of these oppressions, it was concluded that Afghan young adults in post-secondary institutions are in need of mental health intervention services and funding that creates space for the promotion of a sense of belonging and acceptance. Educational institutions should also create services, groups, scholarships, and accommodation policies that are sensitive and accessible to all and allow for equity. 


\section{Appendix I}

RYERSON

UNIVERSITY
Ryerson University

Consent Agreement

You are being invited to participate in a research study. Please read this consent form so that you understand what your participation will involve. Before you consent to participate, please ask any questions to be sure you understand what your participation will involve.

\section{Exploring the mental health experiences of Afghan diasporic post-secondary students in Toronto Canada.}

INVESTIGATORS: This research study is being conducted by Naro Hussaini, a Master of Social Work student. Gordon Pon, BSW, MSW, PhD is the supervisor for this student's research project. He is a professor of Ryerson University's School of Social Work.

If you have any questions or concerns about the research, please feel free to contact Naro Hussainivia email@ Nargis.hussaini@ryerson.ca

PURPOSE OF THE STUDY: The purpose of this study is to explore the mental health experiences of Afghan post secondary students in Toronto Canada.

This research is seeking to hear from first generation Afghan-Canadians to centre their experiences and feelings of belonging/not belonging in a Canadian post-secondary setting, and/or experiences of discrimination and marginalization. We are also interested in how these experiences impact one's mental health.

Participants must be immigrated to Canada, must identify as Afghan, and must be 17-30 years of age, and must be enrolled full-time/part-time in one of the post-secondary school in Toronto Canada.

This research is being completed by Naro Hussaini, a graduate student in the School of Social Work. The results will contribute to her major research paper in partial completion of her Master's degree.

PARTICIPATION: If you volunteer to participate in this study, you will be invited to do the following things:

- Read through consent form and ask for clarification if necessary, and sign

- Interviews may take place in a secure office room in the School of Social Work or Library at Ryerson University in which aural and visual privacy can be ensured

- Participants may choose a location of their preference (including their personal residence) 
- This may need further discussion in order to ensure the safety of both the participant and the researcher

- Provide demographic information including:

- Age, gender, ethnic identification, mother tongue/ other language fluency, family structure (nuclear), educational attainment

- Participate in one face-to-face interview lasting approximately 60-90 minutes

- Sample questions include:

- Participate in one face-to-face interview lasting approximately 60-90 minutes

- Sample questions include:

- Demographic information:

- Why did you decide to participate in this study?

- What does a day in your life look like? (What duties does it consist of?)

- What did you imagine campus life to be like, how is it different in reality?

- How strong is your sense to belonging to your campus? Explain

- What are some of the most difficult experiences you have faced in an academic setting as a result of being a racial minority?

- How did you make sense of those experiences?

- Be audio-recorded during the interview so that the researcher may transcribe the interview afterwards

- Participants will be contacted by the researcher following interviews to do member check-ins to ensure that the data collected and interpreted resonate with participants

- Upon the completion of the research paper, the participants will have a copy of the paper delivered to them by the method of their choice (if they want it); by mail, e-mail, or personal delivery by the researcher.

POTENTIAL BENEFITS: The potential benefits of this research to participants is minimal. However, it will provide them a space to speak about their experiences in which their voices are centered. It will provide some insight for those who decide to read my major research paper on the unique mental health experiences of the few Afghan postsecondary students, and it will add to literature and suggest future research area in this community.

I cannot guarantee, however, that you will receive any benefits from participating in this study.

\section{WHAT ARE THE POTENTIAL RISKS TO YOU AS A PARTICIPANT?}

The potential risks or harms involved in this study are minimal. Within this research there is a personal identity risk as participants will be known to the researcher, as such their identities will not be anonymous. However, the researcher will maintain their confidentiality which is further detailed in the section below regarding confidentiality. During the interview, there is the potential risk that participants may experience psychological discomfort while disclosing and/or recalling past experiences that may have impacted their identity constructions and/or conflicts within the home or school environment. 
As such, a list of resources will be provided at the end of this consent form for participants to keep if they wish to access services or support. Participants have the right to skip questions, take a break, or discontinue the interview at any time. If participants decide to withdraw from the study, any information collected will be destroyed.

After the interview, the researcher will again check-in with the participant and offer information about how to access support services. The researcher will also advise the participant that the participant can contact the researcher at any time for information about accessing support services.

\section{CONFIDENTIALITY:}

The researcher, Naro Hussaini, and her supervisor, Gordon Pon, will be the only ones to have access to the research data, in which all data will only ever be kept by the single researcher, Naro Hussaini. The researcher will engage in member-check-ins, in which participants will have access to their own data.

Signed consent forms, audio-recorded interviews, interview transcriptions, and contact information (names, e-mail, and/or phone-number) will be collected. Participant's e-mail and/or phone number are collected for the sole purpose of facilitating interview arrangement and correspondence with participants during the research process. The information will be kept confidential and securely stored electronically with password protection, encrypted USB and deleted once the data has been coded and analyzed. This information may be kept by the researcher for up to 7 years, consistent with records management standards of the Ontario College of Social Workers and Social Service Workers in the event the research pursues further studies. None of this information will ever be used in the research publication. Participants' identities will be protected as pseudonyms of their choosing will replace their names.

All digital data will be stored electronically under password protected files solely in the researcher's computer. Signed consent forms will be kept in a secured locker which is kept in a secure room only accessible to the researcher.

The audio-recordings will be password protected on the audio device and uploaded to password protected audio files. These audio files will be deleted once the transcriptions are completed which is anticipated to be within a week of the interview being audiorecorded. Participants have the right to review and/or edit the audio-recordings or transcripts. At this point, the transcriptions will be kept as password protected files up until the final draft of the paper is completed and submitted to the School of Social Work of Ryerson University. This is anticipated for mid to late August 2017. Once the paper is submitted to the School of Social Work at Ryerson University, the transcriptions will be destroyed. The transcriptions are only kept until the final publication for the purpose of the researcher being able to review them and write their major research paper. 


\title{
COSTS TO PARTICIPATION:
}

There may be some costs if the participant must pay for parking or transit in meeting for the interview. The researcher will reimburse the participant for these costs.

\section{VOLUNTARY PARTICIPATION AND WITHDRAWAL:}

Participation in this study is completely voluntary. You can choose whether to be in this study or not. If any question makes you uncomfortable, you can skip that question. If you choose to stop participating, you may also choose to not have your data included in the study. Your choice of whether or not to participate will not influence your future relations with Ryerson University or the investigator (Naro Hussaini) involved in the research.

\section{QUESTIONS ABOUT THE STUDY:}

If you have any questions about the research now, please ask. If you have questions later about the research, you may contact:

\author{
Naro Hussaini, Master of Social Work Student \\ E-mail: Narogis.hussaini@ ryerson.ca \\ Or \\ Gordon Pon , BSW, MSW, PhD, Supervisor \\ E-mail: g2pon@ryerson.ca \\ Phone: 416) 979-5000 ext.4786
}

This study has been reviewed by the Ryerson University Research Ethics Board. If you have questions regarding your rights as a participant in this study, please contact:

\author{
Research Ethics Board \\ c/o Office of the Vice President, Research and Innovation \\ Ryerson University \\ 350 Victoria Street \\ Toronto, ON M5B 2K3 \\ 416-979-5042 \\ rebchair@ryerson.ca
}

\section{Exploring the mental health experiences of Afghan diasporic post-secondary students in Toronto Canada.}

\section{CONFIRMATION OF AGREEMENT:}

Your signature below indicates that you have read the information in this agreement and have had a chance to ask any questions you have about the study. Your signature also indicates that you agree to participate in the study and have been told that you can change your mind and withdraw your consent to participate at any time. You have been given a copy of this agreement. 
You have been told that by signing this consent agreement you are not giving up any of your legal rights.

Name of Participant (please print)

Signature of Participant

Date

I agree to be audio-recorded for the purposes of this study. I understand how these recordings will be stored and destroyed.

$\overline{\text { Signature of Participant }}$

Date 


\section{Appendix II - Interview Guide}

The interview today will be audio recorded to support the analysis of the data. Audio files will be stored on a password protected, encrypted USB and deleted once the data has been coded and analyzed. Names and other identifying information will not be part of the analysis. You will only be identified by a unique participant code assigned to you. Demographic information such as your age, gender, immigration status, ethnicity, will be collected.

Are you okay to go ahead with the interview?

Now that we have reviewed the consent process, do you have any questions before we begin?

[Turn recorder on and inform participant audio recorder is turned on]

For the benefit of the consent process, can I ask you to confirm that you are okay to proceed with the interview?

[Begin interview]

a) Demographic information:

b) Age

c) Gender

d) Number of years residing in Canada

e) Education level

1. Can you tell me little bit about your family/immigration process?

2. Why did you decide to participate in this study?

3. Tell me about what a typical day in your life is like? (What duties does it consist of?)

4. What is a typical day on campus like for you?

5. What did you imagine campus life to be like? Is it as expected or is it different: If different; How is it different in reality?

6. Can you tell me how strong is your sense of belonging to your campus? Can you give me an example of an incident that made you feel "othered"?

7. What are some of the most difficult experiences you have faced in an academic setting as a result of being a racial minority? 
8. How did you make sense of those experiences?

9. Did it affect your mental heath?
a. If yes: How did these experiences affect your mental health and other domains in your life?
b. How did you make sense of these experiances?
c. How do you define mental health?
d. Are you able to talk about mental health in your language?
e. How did you talk to your family members/friends/supporters about this?

10. If you could improve the situation for others in the same situation, how would you do that? What would the institution need to do? What about your professors and peers?

11. Who/what were your key supports?

12.

13. Would you like a copy of recruitment email/notice to pass on to others who may be interested in this study?

14. Is there anything else that we have not yet covered and you want to talk about?

15. We would like to share the study findings/MRP with you, if you would like to receive the findings, what is the best way to contact you to share this information? 


\section{Appendix III: Recruitment Script}

\section{Are you an Afghan-Canadian post-secondary student in Toronto?}

We are seeking 2-3 immigrant Afghan-Canadian post-secondary students to participate in a new study and help us understand their mental health experiences.

This research is seeking to hear from immigrant Afghan-Canadians to centre their experiences and feelings of belonging/not belonging in a Canadian post-secondary setting, and/or experiences of discrimination and marginalization. We are also interested in how these experiences impact one's mental health.

One-on-one in person or over the phone confidential interviews with participants will be 60 to 90 minutes. All data will be encrypted and kept confidential.

For more information and to participate in this new study, please contact Nargis.hussaini@ryerson.ca

This research is being completed by Naro Hussaini, a graduate student in the School of Social Work. The results will contribute to her major research paper in partial completion of her Master's degree.

The final paper will be submitted to the School of Social Work and stored at the University such that it could be accessed by students.

This research study has been approved by Ryerson Research Ethics Board 2016-234. This research study is funded by the Ryerson Health Research Fund and the Faculty of Community Services Seed Grant, Ryerson University 


\section{References}

Agyekum, B., \& Newbold, K. B. (2016). Sense of place and mental wellness of visible minority immigrants in Hamilton, Ontario: Revelations from Key Informants. Canadian Ethnic Studies, 48(1), 101-122.

Azimi, A. (2004) The mental health crisis in Afghanistan. http://www.afgha.com/?af=article $\&$ sid=41671

Chotani, R., Khan, M.I., Khan, S., \& Laaser, U. ( 2003) - Child health in Afghanistan: A glimpse on the future of a war stricken country. http://www.ayubmed.edu.pk/JAMC/PAST/15-1/Ibrahim\%20Afghan.htm

Dossa, P. (2008). Creating politicized spaces: Afghan immigrant women's Stories of migration and displacement. Affilia: Journal of Women and Social Work, 23(1), 10-21. http://doi.org/10.1177/0886109907310462

Delgado, R. (1982). Words that wound: A tort action for racial insults, epithets, and name-calling. Harvard Civil Rights-Civil Liberties Law Review, 17, 133-136.

Delgado, R., \& Stefancic, J. (2012). Chapter 1. In Critical race theory: An introduction (pp. 1-16). New York: New York University Press. doi:9780814785294

Edge, S, . \& Newbold, B. (2012). Discrimination and the health of immigrants and refugees: Exploring Canada's evidence base and directions for future research in newcomer receiving countries. Journal of Immigrant and Minority Health, 15 (1): 141148.

Gastaldo, D. (2014). Biographical erasure as oppression: Biographical erasure as newcomers to Canada. British Journal of Social Work, 1 (2368-0016)189-206.

Gallina, M., \& Williams, A. (2014). Variations in sense of place across Immigrant 
status and gender in hamilton, Ontario; Saskatoon, Saskatchewan; and, Charlottetown, Prince Edward Island, Canada. Social Indices Research 121: 241-252

Hagerty, B. M. K., Lynch-Sauer, J., Patusky, K., Bouwsema, M., \& Collier, P. (1992). Sense of belonging: A vital mental health concept. Archives of Psychiatric Nursing, 6, 172-177.

Kassin, S., Fein, S., Markus, H. R., \& Burke, T. (2013). Stereotypes, prejudice, and discrimination. In Social Psychology ( $2^{\text {nd }}$ Canadian Edition.). Toronto: Nelson Education.

Khanlou, N., Koh, J. G., \& Mill, C. (2008). Cultural identity and experiences of prejudice and discrimination of Afghan and Iranian immigrant youth. International Journal of Mental Health and Addiction, 6(4), 494-513. http://doi.org/10.1007/s11469008-9151-7

Mann, G. (2008). Doing nothing and being good: Social relationships and networks of support among adolescent Congolese refugees in Dar es Salaam. In J. Hart (Ed.), Years of conflict: Adolescence, political violence and displacement (pp. 38-57). New York: Berghahn Books.

Meeuwisse, M., Severiens, S. E., \& Born, M. P. (2010). Learning environment, interaction, sense of belonging and study success in ethnically diverse student groups. Research in Higher Education, 51(6), 528-545.

Oppedal, B., Røysamb, E., \& Sam, D. L. (2004). The effect of acculturation and social support on change in mental health among young immigrants. International Journal of Behavioral Development, 28(6), 481-494.

Reitmanova, S., \& Gustafson, D. L. (2009). Mental health needs of visible 
minority immigrants in a small urban center: Recommendations for policy makers and service providers. Journal of Immigrant and Minority Health, 11(1), 46-56. http://doi.org/10.1007/s10903-008-9122-x

Sadat, M. H. (2008). Hyphenating Afghaniyat (Afghan-ness) in the Afghan diaspora. Journal of Muslim Minority Affairs, 28(3), 329-342. http://doi.org/Article

Shakya Y, Khanlou N, \& Gonsalves T. (2010). Determinants of mental health for newcomer youth: policy and service implications. Canadian Issues/ Themes Canadiens, Summer, 98-102.

Statistics Canada. (2013b). NHS Focus on Geography Series - Toronto: Immigration and ethnocultural diversity. Ottawa: Retrieved from http://www12.statcan.gc.ca/nhsenm/2011/assa/fogsspg/Pages/FOG.cfm?lang=E\&level=3 $\&$ GeoCode $=535$.

Stebleton, M. J., Soria, K. M., \& Huesman, R. L. J., \& Torress, V. (2014). Recent immigrant students at research universities: The relationship between campus climate and sense of belonging. Journal of College Student Development, 55(2), 196-202.

Soroor, W., \& Popal, Z. (2005). Bridging the Gap: Understanding the mental health needs of Afghan youth. Toronto, Ontario, Canada.

Solozano, D. G., \& Yosso, T.J. (2002). Critical race methodology: Counter-story-telling as an analytical framework for education research. Qualitative Inquiry, 8(1), 23-44.

Quirke, L. (2014). A study of the information practices of Afghan newcomer youth in the contexts of leisure and settlement. (Unpublished doctoral dissertation.) University of Toronto.

Quirke, L. (2011). Exploring the settlement experiences and information practices 
of Afghan newcomer youth in Toronto. The Canadian Journal of Information and Library Science, 35, 345-353.

World Health Organization (WHO). 2001. World health report 2001: mental health: New Understanding, New Hope.

http://www. who.int/mediacentre/factsheets/fs220/en.

World Health Organization (WHO). 2016. Mental Health: Strengthening Mental Health Promotion. Fact Sheet \# 220.

http://www.who.int/mediacentre/factsheets/fs220/en/

Xu, M. A., \& McDonald, J. T. (2010). The mental health of immigrants and minorities in Canada: The social and economic effects. Canadian Issues, 29-31. 
- 1 - 